\title{
STANDARISASI RESEP RANDANG DAREK DAN RANDANG PASISIA SEBAGAI MAKANAN TRADISIONAL DI SUMATERA BARAT
}

\author{
Yolanda Intan Sari, Yuliana \\ Program Pascasarjana Prodi Pendidikan Kesejahteraan Keluarga, Fakultas Teknik, Universitas Negeri Padang, \\ Jl. Prof. Dr. Hamka, Air Tawar Bar., Kec. Padang Utara, Kota Padang, Sumatera Barat 25171 \\ Email: yolandaintan16@gmail.com
}

\begin{abstract}
Abstrak
Penelitian ini bertujuan untuk menstandarkan resep randang daging wilayah darek dan wilayah pasisia di Sumatera Barat. Wilayah darek adalah daerah yang berada di daerah pengunungan salah satunya Payakumbuh. Sedangkan wilayah pasisia adalah daerah yang berada di sepanjang pingiran pantai yaitu Kota Pariaman. Penelitian ini mengunakan metode kombinasi (Mixed Methode) dengan pendekatan sequential exploratory. Sumber data penelitian adalah 10 orang informan UMKM yang mewakili 5 daerah darek dan 5 daerah pasisia. Data penelitian berupa hasil observasi dan wawancara kepada informan, serta pengamatan pada lokasi penelitian. Hasil dari penelitian yang telah dilakukan menunjukan bahwa bervariasinya resep radang daging yang ada di daerah darek dan pasisia, terlihat dari di dapatkannya 10 resep randang daging dari dua daerah yang dijadikan tempat penelitian memiliki perbedan baik itu dari komposisi bahan maupun teknik pengolahannya sehingga kualitas yang dihasilkan dari setiap randang daging bervariasi. Dari 5 resep yang didapatkan di daerah darek di lakukan standarisasi terhadap resep yang mempunyai nilai kualitas tertinggi dan untuk 5 resep daerah pasisia juga di lakukan standarisasi terhadap resep yang mempunyai nilai kualitas tertinggi yang telah dinilai oleh panelis.
\end{abstract}

Kata Kunci: Iventarisasi, Standarisasi, Resep, Darek, Pasisia

\begin{abstract}
This study aims to standardize the recipe for meat randang in Darek and Pasisia regions in West Sumatra. Darek area is an area located in a mountainous area, one of which is Payakumbuh. Meanwhile, the Pasisia region is an area along the coast, namely Kota Pariaman. This study uses a mixed method with a sequential exploratory approach. Sources of research data were 10 MSME informants representing 5 Darek areas and 5 Pasisia regions. The research data is in the form of observations and interviews with informants, as well as observations at the research location. The results of the research that have been carried out show that the variations in the recipe for inflammation of the meat in the Darek and Paci fic areas, can be seen from the 10 recipes for meat randang from the two regions used as the research site. each meat cage varies. Of the 5 recipes obtained in the Darek area, the recipes that had the highest quality value were standardized and for the 5 recipes from the Pasisia region, the recipes that had the highest quality value were standardized as assessed by the panelists.
\end{abstract}

Keywords: Inventory, Standardization, Recipe, Darek, Pasisia

\section{Pendahuluan}

Provinsi Sumatera Barat memiliki keindahan alam beragam adat istiadat dan kebudayaan serta makanan tradisional. Makanan tradisional Sumatera Barat dikenal oleh masyarakat baik lokal maupun mancanegara. Marwanti (2000:12) mengatakan bahwa, Makanan rakyat yang dikonsumsi dalam lingkungan masyarakat tertentu dan diturunkan secara turun menurun disebut makanan tradisional. Salah satu makanan tradisional dari Sumatera Barat adalah randang daging. Randang daging atau induak jamba merupakan hidangan wajib di sajikan setiap acara adat. Randang harus dijaga dan dilestarikan keasliaannya. Menurut Wynda (2019:33), Pada tanggal 7 April 2011 randang daging dinobatkan sebagai makanan nomor 1 terenak di dunia versi CNN (sebuah saluran berita kabel AS dan saluran TV pertama yang menyiarkan liputan berita 24 jam).

Randang daging yang ada di daerah Sumatera Barat memiliki aroma dan rasa khas yang berbeda disetiap wilayahnya. Perbedaan ini disebabkan oleh penggunaan bumbu/rempah maupun teknik pengolahan. Sumatera Barat terdiri dari wilayah darek dan wilayah pasisia. Wilayah darek adalah sebutan untuk daerah pegunungan di Sumatera Barat seperti Padang Panjang, Bukittinggi, Agam, Tanah Datar, dan Payakumbuh (Hanifa dkk, 2017:48). Wilayah pasisia merujuk pada dataran rendah di bagian Barat dari Bukit Barisan (Elfira M, 2018:3). Daerah pasisia yaitu Pariaman, Padang Pariaman, Kota Padang, Pesisir Selatan dan Tiku (Pusat Data dan Analisis Tempo, 2019:71). 
Randang daging yang berasal dari wilayah darek memiliki intensitas warna hitam, aroma asap dan rasa yang lebih dominan (Nazir, dkk 2018:602). Untuk teknik pengolahannya yaitu dengan merebus semua bumbu dan daging dalam santan, diaduk perlahan hingga kuahnya kering. Berbeda dengan randang daging wilayah pasisia, randang wilayah pasisia memiliki bumbu yang kaya rempah, sehingga aroma rempahnya lebih terasa (Tempo.co:2012). Untuk Teknik pengolahan randang pasisia yaitu bumbu yang digunakan ditumis dan ditambah dengan ketumbar.

Dari perbedaan resep wilayah darek dan wilayah pasisia apabila diolah oleh orang yang berbeda maka kualitas rasa randang daging yang dihasilkan tidak akan sama. Apalagi resep yang disampaikan masyarakat dari mulut ke mulut dan secara turun temurun, dikhawatirkan akan terjadinya perbedaan informasi yang diterima ke generasi berikutnya. Maka sangat diperlukan standarisasi resep dari randang daging, agar untuk generasi selanjutnya tidak ada perbedaan kualitas randang daging baik itu wilayah darek maupun wilayah pasisia dilihat dari segi bentuk, warna, aroma, tekstur, dan rasa.

Produksi randang daging memiliki potensi besar dan layak dikembangkan untuk mendukung sektor ekonomi dan juga pariwisata di Kota Payakumbuh dan Kota Pariaman. Maka dari itu peran UMKM sangatlah membantu dalam pengembangan dan inovasi dari randang daging yang telah distandarkan, dilihat dari komposisi bahan dan teknik pengolahannya. Pertumbuhan UMKM dapat menghasilkan program yang strategis, yakni program kewirausahaan dan program kemitraan (Hadiyati, 2011:9). Hasil dari inovasi randang inilah nantinya yang akan menjadi program kewirausahaan, dimana resep randang yang telah di standarisasi ini menjadi basis dalam pengembangan sumber daya manusia. Sehingga dengan adanya penelitian ini menambah wawasan masyarakat tentang pentingnya makanan tradisional dan mengetahui adanya perbedaan dari randang daging sesuai dengan asal tempat pengolahannya. Serta dapat menjaga khasanah budaya makanan tradisional karena merupakan ilmu yang turun temurun akan diwariskan.

\section{Bahan dan Metode Penelitian}

Jenis penelitian yang digunakan adalah metode campuran (Mixed Methode) dengan mengunakan pendekatan sequential exploratory, penelitian ini merupakan metode gabungan antara metode deskriptif kualitatif dan kuantitatif. Menurut Sugiyono (2018:404) metode kombinasi adalah metode penelitian yang mengabungkan antara metode kualitatif dan kuantitatif yang digunakan secara bersamaan.

Jenis data yang digunakan dalam penelitian adalah data primer dan sekunder. Data primer merupakan data yang diambil dari panelis uji organoleptik terhadap randang daging meliputi bentuk, warna, tekstur dan rasa. Data sekunder adalah data yang mendukung data primer yaitu nama-nama UMKM yang ada di daerah darek Kota Payakumbuh dan daerah pasisia Kota Pariaman.

Instrument penelitian kualitatif ini dilakukan dengan cara wawancara, observasi, dan dokumentasi tentang resep randang daging meliputi: komposisi bahan yang digunakan, jumlah takaran bahan dan teknik pengolahan randang daging. Instrument penelitian kuantitatif yaitu angket uji organoleptik standarisasi resep randang daging dari segi (bentuk, warna, aroma, tekstur dan rasa).

Teknik pengumpulan data yang digunakan dalam penelitian ini adalah observasi, wawancara, dan dokumentasi. Teknik analisis data kualitatif yang meliputi tiga alur kegiatan antara lain reduction (data reduksi), data display (penyajian data) data verifikasi (menarik kesimpulan).

\section{Hasil dan Pembahasan \\ Hasil}

1. Resep randang daging

a. Bahan yang digunakan dalam mengolah randang daging

Berdasarkan hasil wawancara dengan 5 orang informan yang mewakili daerah darek Kota Payakumbuh dapat disimpulkan bahwa bahan yang digunakan dalam pengolahan randang daging adalah daging, santan, cabe, bawang merah, bawang putih, jahe, lengkuas, daun kunyit, daun jeruk dan sereh.

Hasil wawancara dengan 5 orang informan yang mewakili daerah pasisia Kota Pariaman dapat disimpulkan bahan yang digunakan dalam pengolahan randang daging adalah daging, santan, cabe, bawang merah, bawang putih, jahe, lengkuas, daun kunyit, daun jeruk, sereh dan rempah (kayu manis, cengkeh, kapulaga, ketumbar, merica, bunga lawang).

b. Jumlah takaran bahan yang digunakan dalam pengolahan randang daging

Berdasarkan hasil wawancara dan dokumentasi disimpulkan bahwa jumlah takaran bahan yang digunakan dalam pengolahan randang daging berdasarkan daerah tempat pengolahan yaitu:

Daerah darek: Daging $1 \mathrm{~kg}$, santan kental 690 $\mathrm{ml}$, santan cair $2000 \mathrm{ml}$, cabe giling 250 gr, bawang putih 70 gr, bawang merah 100 gr, jahe 20 gr, laos 100 gr, daun jeruk 3 gr, daun kunyit 12 gr, sereh 40 gr.

Pasisia: Daging $1 \mathrm{~kg}$, santan kental $750 \mathrm{ml}$, santan cair 3190, cabe giling $250 \mathrm{gr}$, bawang putih $57 \mathrm{gr}$, bawang merah 84 gr, jahe 19 gr, laos 54 gr, pala 6 gr, kayu manis $3 \mathrm{gr}$, ketumbar $4 \mathrm{gr}$, bunga lawang $1 \mathrm{gr}$, cengkeh 1 gr, kapulaga 1 gr, dun jeruk 3 gr, daun kunyit 17 gr, sereh 32 gr, garam 19 gr.

c. Cara membuat randang daging

Dari hasil wawancara yang dilakukan dengan 5 orang informan yang mewakili daerah darek Kota Payakumbuh dapat disimpulkan bahwa cara pengolahan randang daging yaitu:

1) Persiapkan alat dan bahan yang diperlukan 
2) Potong dan cuci bersih daging

3) Parut kelapa dan laos dengan mesin pemarut kelapa

4) Kemudian peras kelapa dan laos dengan mesin pemeras santan

5) Haluskan semua bumbu

6) Memarkan sereh, dan siapkan daun-daunan

7) Tuangkan santan kedalam wajan, tambahkan semua bumbu yang telah dihaluskan

8) Aduk sampai mendidih, setelah mendidih masukan daun-daunan serta daging yang telah dipotong

9) Aduk terus sampai randang bewarna coklat kehitaman dan kering

10) Setelah kering angkat dan hidangkan

Dari hasil wawancara yang dilakukan dengan 5 orang informan mewakili daerah pasisia Kota Pariama dapat disimpulkan bahwa cara pengolahan randang daging yaitu:

1) Persiapkan alat dan bahan yang diperlukan

2) Potong dan cuci bersih daging

3) Parut kelapa kemudian peras dan ambil santannya

4) Haluskan semua bumbu, memarkan sereh, siapkan daun-daunan dan rempah

5) Masukan sedikit minyak kedalam wajan, tumis semua bumbu halus dan cabe giling hingga aroma keluar

6) Tambahkan daun-daunan dan santan kedalamnya

7) Aduk sampai mendidih dan sedikit terbit minyak

8) Setelah mendidih masukan daging yang telah dipotong

9) Aduk terus sampai randang bewarna coklat kehitaman dan kering

10) Setelah kering angkat dan hidangkan

2. Proses menstandarkan resep randang daging

Proses menstandarkan resep randang daging di daerah darek Kota Payakumbuh dan daerah pasisia Kota Pariaman meliputi: komposisi bahan yang digunakan, jumlah takaran bahan, dan teknik pengolahan. Standarisasi resep ini diperoleh dari uji organoleptik kepada 10 orang masyarakat di setiap daerah yang telah dipilih.

a. Standarisasi resep randang daging daerah darek Kota Payakumbuh

Standarisasi randang daging diperoleh dengan melakukan uji organoleptik awal terhadap 5 resep randang daging yang didapat di daerah darek oleh masyarakat. Masyarakat yang di pilih merupakan 10 orang perwakilan daerah darek yang paham dengan randang daging. Setelah dilakukan uji organoleptik terhadap 5 resep randang daging darek di peroleh 3 resep perwakilan daerah darek yang memiliki rata-rata nilai tertinggi. Uji organoleptik ke dua dilanjutkan terhadap 3 resep dengan nilai rata-rata tertinggi. Setelah didapatkan 1 resep dengan rata-rata tertinggi maka resep tersebut akan dijadikan resep standar dengan takaran komposisi bahan yang telah di konversikan.

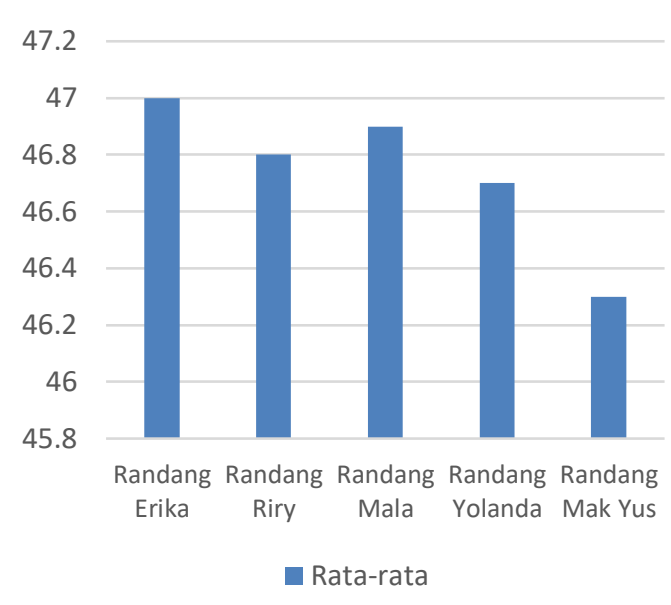

Grafik I rata-rata hasil uji organoleptik 5 resep randang daging di daerah darek Kota Payakumbuh

Berdasarkan data di atas dapat diketahui bahwa perolehan skor yang tertinggi dari lima resep randang daging yaitu resep randang erika, randang mala dan randang riry. Dari tiga resep randang tersebut penulis memilih satu yang terbaik menurut 10 orang masyarakat yang telah mencicipi dan menilai randang daging dengan data yang dapat dilihat pada grafik 2 :

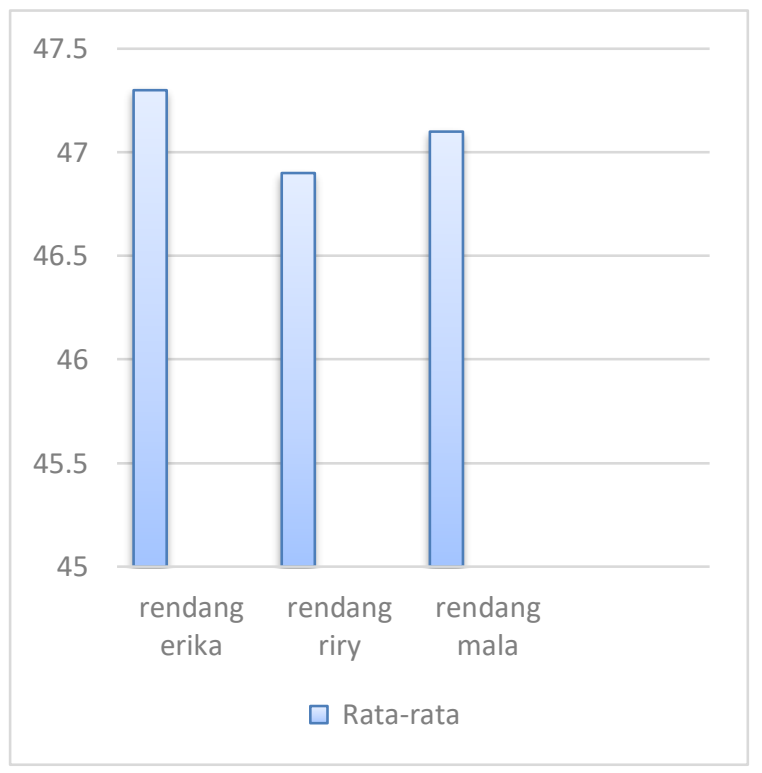

Grafik II rata-rata hasil uji organoleptik 3 resep randang daging di daerah darek Kota Payakumbuh

Berdasarkan grafik diatas dapat diketahui bahwa kualitas randang tertinggi yaitu pada grafik pertama dengan rata-rata 47,3 yang diolah oleh Rendang Erika, maka karena memiliki kualitas terbaik resep dari Rendang Erika yang dipilih dan dijadikan sebagai resep standar untuk daerah darek Kota Payakumbuh. 
Tabel I resep randang darek Kota Payakumbuh yang telah di konversikan

\begin{tabular}{|c|c|c|c|}
\hline $\begin{array}{c}\text { Resep } \\
\text { Randang }\end{array}$ & Banyak & $\begin{array}{c}\text { Resep yang } \\
\text { dikonversikan }\end{array}$ & Banyak \\
\hline Daging & $\begin{array}{l}1 \mathrm{~kg} 28 \\
\text { potong }\end{array}$ & Daging & $1 \mathrm{~kg}$ \\
\hline Santan & $\begin{array}{l}4 \text { butir } \\
\text { kelapa }\end{array}$ & Santan kental & $690 \mathrm{ml}$ \\
\hline Cabe giling & $\pm 250 \mathrm{gr}$ & Santan cair & $2000 \mathrm{ml}$ \\
\hline $\begin{array}{c}\text { Bawang } \\
\text { putih }\end{array}$ & $5 \mathrm{sdm}$ & Cabe giling & $250 \mathrm{gr}$ \\
\hline $\begin{array}{l}\text { Bawang } \\
\text { merah }\end{array}$ & $100 \mathrm{gr}$ & Bawang putih & $70 \mathrm{gr}$ \\
\hline Jahe & Sck & Bawang merah & $100 \mathrm{gr}$ \\
\hline Laos & Sck & Jahe & $20 \mathrm{gr}$ \\
\hline Daun jeruk & Sck & Laos & $100 \mathrm{gr}$ \\
\hline $\begin{array}{c}\text { Daun } \\
\text { kunyit }\end{array}$ & Sck & Daun jeruk & $3 \mathrm{gr}$ \\
\hline \multirow[t]{2}{*}{ Sereh } & Sck & Daun kunyit & $12 \mathrm{gr}$ \\
\hline & & Sereh & $40 \mathrm{gr}$ \\
\hline
\end{tabular}

b. Standarisasi resep randang daging daerah pasisia Kota Pariaman

Standarisasi randang daging diperoleh dengan melakukan uji organoleptik awal terhadap 5 resep randang daging yang didapat di daerah pasisia oleh masyarakat. Masyarakat yang di pilih merupakan 10 orang perwakilan daerah pasisia yang paham dengan randang daging. Setelah dilakukan uji organoleptik terhadap 5 resep randang daging pasisia di peroleh 3 resep perwakilan daerah pasisia yang memiliki rata-rata nilai tertinggi. Uji organoleptik ke dua dilanjutkan terhadap 3 resep dengan nilai rata-rata tertinggi. Setelah didapatkan 1 resep dengan rata-rata tertinggi maka resep tersebut akan dijadikan resep standar dengan takaran komposisi bahan yang telah di konversikan.

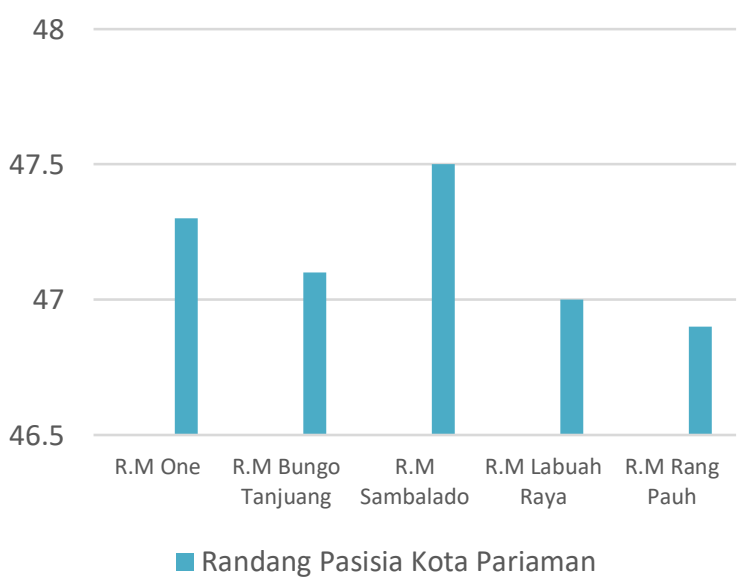

Grafik III rata-rata hasil uji organoleptik 5 resep randang daging di daerah Pasisia Kota Pariaman
Berdasarkan data di atas dapat diketahui bahwa perolehan skor yang tertinggi dari lima resep randang daging yaitu resep Rumah makan one, Rumah makan bungo tanjung, Rumah makan sambalado. Dari tiga resep randang tersebut penulis memilih satu yang terbaik menurut 10 orang masyarakat yang telah mencicipi dan menilai randang daging dengan data yang dapat dilihat pada grafik 4

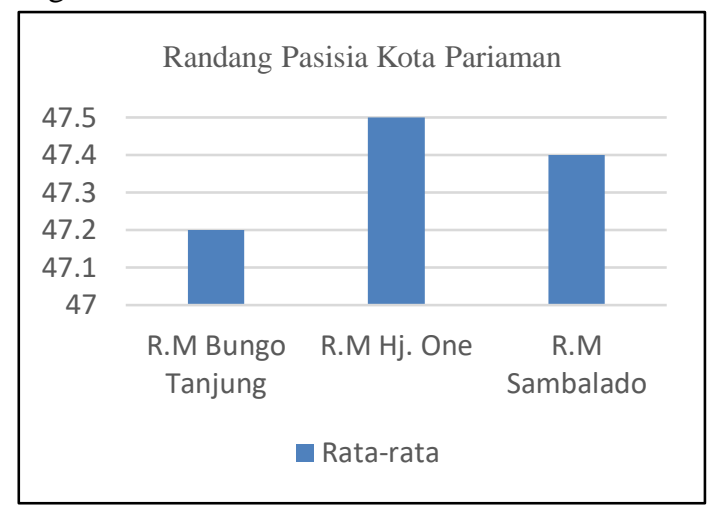

Grafik 4 rata-rata hasil uji organoleptik 5 resep randang daging di daerah Pasisia Kota Pariaman

Berdasarkan grafik diatas dapat diketahui bahwa kualitas randang tertinggi yaitu pada grafik kedua dengan rata-rata 47,5 yang diolah oleh rumah makan Hj.One, maka karena memiliki kualitas terbaik resep dari rumah makan Hj.One yang dipilih dan dijadikan sebagai resep standar untuk daerah pasisia Kota Pariaman.

Tabel 2 resep randang pasisia Kota Pariaman yang telah di konversikan

\begin{tabular}{|c|c|c|c|}
\hline Resep & Banyak & $\begin{array}{c}\text { Resep yang } \\
\text { dikonversikan }\end{array}$ & Banyak \\
\hline $\begin{array}{c}\text { Daging } \\
\text { Sapi }\end{array}$ & $\begin{array}{l}1 \mathrm{~kg} 17 \\
\text { potong }\end{array}$ & Daging Sapi & $\begin{array}{l}1 \mathrm{~kg} 17 \\
\text { potong }\end{array}$ \\
\hline Santan & $\begin{array}{l}3 \text { butir } \\
\text { kelapa }\end{array}$ & Santan kental & $750 \mathrm{ml}$ \\
\hline $\begin{array}{l}\text { Cabe } \\
\text { giling }\end{array}$ & $250 \mathrm{gr}$ & Santan cair & $3190 \mathrm{ml}$ \\
\hline $\begin{array}{c}\text { Bawang } \\
\text { putih }\end{array}$ & $\begin{array}{c}1 \\
\text { bulatan } \\
\text { kecil }\end{array}$ & Cabe giling & $250 \mathrm{gr}$ \\
\hline $\begin{array}{c}\text { Bawang } \\
\text { merah }\end{array}$ & $\begin{array}{c}2 \\
\text { gengam }\end{array}$ & Bawang putih & $57 \mathrm{gr}$ \\
\hline Jahe & $\begin{array}{l}2 \text { ruas } \\
\text { jari }\end{array}$ & Bawang merah & $84 \mathrm{gr}$ \\
\hline Laos & $\begin{array}{l}3 \text { ruas } \\
\text { jari }\end{array}$ & Jahe & $19 \mathrm{gr}$ \\
\hline Pala & 1 biji & Laos & $54 \mathrm{gr}$ \\
\hline $\begin{array}{l}\text { Kayu } \\
\text { manis }\end{array}$ & $\begin{array}{l}1 \text { batang } \\
\text { kecil }\end{array}$ & Pala & $6 \mathrm{gr}$ \\
\hline Ketumbar & $1 \mathrm{sdm}$ & Kayu manis & $3 \mathrm{gr}$ \\
\hline $\begin{array}{l}\text { Daun } \\
\text { jeruk }\end{array}$ & 5 helai & Ketumbar & $4 \mathrm{gr}$ \\
\hline $\begin{array}{l}\text { Bunga } \\
\text { Lawang }\end{array}$ & sck & Bunga Lawang & $1 \mathrm{gr}$ \\
\hline
\end{tabular}




\begin{tabular}{cccc}
\hline Resep & Banyak & $\begin{array}{c}\text { Resep yang } \\
\text { dikonversikan }\end{array}$ & Banyak \\
\hline Cengkeh & sck & Cengkeh & $1 \mathrm{gr}$ \\
\hline Kapulaga & sck & Kapulaga & $1 \mathrm{gr}$ \\
\hline $\begin{array}{c}\text { Daun } \\
\text { kunyit }\end{array}$ & 1 helai & Daun jeruk & $3 \mathrm{gr}$ \\
\hline Sereh & 1 batang & Daun kunyit & $17 \mathrm{gr}$ \\
\hline garam & sck & Sereh & $32 \mathrm{gr}$ \\
\hline \multicolumn{4}{c}{ Garam } \\
\hline
\end{tabular}

Cara Membuat

- Siapkan semua bahan yang akan digunakan dalam pengolahan randang danging

- Potong daging menjadi 17 potong

- Peras kelapa, kemudian haluskan bawang merah, bawang putih, jahe dan pala

- Setelah semua bahan yang diperlukan selesai, masukan sedikit minyak kedalam wajan

- Tumis cabe giling serta bumbu-bumbu halus dan daun-daunan hingga aroma keluar

- Kemudian tambahkan santan dan aduk hingga rata, masak sampai terbit minyak (kalio) lebih kurang 2 jam

- $\quad$ Setelah terbit minyak (kalio) masukan daging kedalamnnya dan tambahkan rempah yaitu cengkeh, bunga lawang, kapulaga dan kayu manis

- $\quad$ Aduk terus masak hingga menjadi randang (dari awal pengolahan \pm 5 jam)

\section{Pembahasan}

1. Resep standar randang daging

Standar adalah sebuah aturan, biasanya digunakan untuk bimbingan tetapi dapat pula bersifat wajib (paling sedikit dalam praktik), memberi batasan spesifikasi dan penggunaan sebuah objek atau karakteristik sebuah proses atau karakteristik sebuah metode (Sulistyo, 2013). Resep adalah keterangan yang menjadikan panduan dalam pengolahan makanan. Berdasarkan hasil penelitian kualitatif meliputi wawancara, observasi dan dokumentasi di daerah darek Kota Payakumbuh dan daerah pasisia Kota Pariaman resep randang daging meliputi: komposisi bahan yang digunakan, jumlah takaran bahan dan teknik pengolahan. Standar resep adalah patokan suatu makanan yang menjadi penjamin keseragaman makanan sehingga kualitas makanan yang diperoleh baik dari segi bentuk, warna, aroma, tekstur dan rasa.

2. Kualitas randang daging

a. Bentuk

Bentuk merupakan tampilan secara keseluruhan dari makanan. Bentuk merupakan kriteria penampilan yang harus ada pada makanan. Bentuk makanan dapat dicetak atau sesuai dengan kreatifitas pembuatnya. Hariadi, dkk (2012:8) berpendapat bahwa, Satu Kg daging biasanya dipotong menjadi 40 bingkah. Bentuk potongan daging yang digunakan dalam pengolahan randang daging itu bervariasi, tergantung dimana tempat

pengolahannya. Karena setiap daerah memiliki ciri khasnya masing-masing

b. Warna

Warna merupakan faktor utama yang diamati oleh konsumen. Menurut Winarno (2004:171), Suatu bahan yang bergizi, enak, dan teksturnya sangat baik, tidak akan dimakan apabila memiliki warna yang tidak sedap dipandang atau memberi kesan telah menyimpang dari warna yang seharusya. Warna randang daging yaitu coklat kehitaman yang dihasilkan dari proses memasak yang lama dari proses pengolah randang daging dan bahan yang digunakan dalam pembuatan randang.

c. Aroma

Aroma yang dihasilkan dapat menambah tingkat penerimaan konsumen terhadap suatu produk. Makanan yang beraroma harum ditentukan oleh pemakaian bahan yang berkualitas. Hal ini diperkuat dengan pendapat Sutomo, (2012:6) Aroma randang sangat khas, legit dan sangat harum.

d. Tekstur

Tekstur adalah susunan yang dapat dirasakan melalui indera peraba baik jari maupun tangan. Menurut Wynda (2019:82), Tekstur daging randang daging adalah empuk karena proses pengolahan yang lama dan daging yang dipilih tidak berlemak. Tekstur yang diharapkan pada randang daging adalah pada bagian bumbu randang daging berminyak dan tekstur daging pada randang empuk karena proses pengolahan yang lama.

e. Rasa

Rasa merupakan aspek terpenting dalam suatu cita rasa masakan. Rasa makanan merupakan faktor kedua yang menentukan cita rasa makanan setelah penampilan makanan itu sendiri, apabila penampilan makanan yang disajikan merangsang saraf melalui indera penglihatan sehingga mampu membangkitkan selera untuk mencicipi makanan itu. Menurut Wynda (2019:33), Rasa randang daging adalah gurih, karena sangat mudah diterima oleh semua lidah. Pada penelitian ini rasa yang diinginkan dari randang daging adalah rasa gurih.

\section{Kesimpulan}

Berdasarkan hasil penelitian dan pembahasan dapat ditarik kesimpulan bahwa hasil randang yang ada di daerah darek Kota Payakumbuh dan dan daerah pasisia Kota Pariaman memiliki perbedaan baik itu dari segi komposi bahan yang digunakan, jumlah takaran bahan, teknik pengolahan serta kualitas yang dihasilkan diihat dari aspek (bentuk, warna, aroma, tekstur dan rasa).

\section{Daftar Pustaka \\ Artikel jurnal:}

1. Hadiyati, E. (2011). Kreativitas dan inovasi berpengaruh terhadap kewirausahaan usaha kecil. Jurnal Manajemen dan Kewirausahaan, 13(1), 8-16.

2. Nazir, N., Anggraini, T., \& Rahayu, L. (2018). Principal Component Analysis For Sensory Profiling 
Of Rendang From Various Region In West Sumatra. International Journal On Advanced Science, Engineering And Information Technology, 8(2), 596603.

Buku :

3. Elfira, M. (2018). Representasi Budaya MatrilinealMaritim Dalam Sastra Lisan Minangkabau, Kaba Anggun Nan Tongga1.

4. Hanifah Hana, Dkk. 2017. Rendang Merantau Dan Minangkabau. Jawa Barat: Bitread Publishing.

5. Hariadi. Ernatip. Silvia Devi. Rismadona. Reza Lahardo. Yulisman. Yoka Y. Agustinawarni. Kardil. Suriani. Nurman. 2012. Inventarisasi Perlindungan Karya Budaya Randang Minangkabau. Padang: Bpsnt Padang Press.

6. Sugiyono, M. S. (2018). Metodologi Penelitian Dilengkapi dengan Metode R\&D.

7. Marwanti. 2000. Pengetahuan Masakan Indonesia. Yokyakarta: Adicita Karya Nusa

8. Wynda Dwi Amalia. 2019. Randang Bundo. Jakarta: Pt Gramedia Pustaka Utama

9. Pusat Data Analisa Tempo. 2019. Menikmati Rendang. Tempo Publishing.

10. Sutomo, B. (2012). Rendang: Juara Masakan Terlezat Sedunia. Kawan Pustaka

11. Winarno, F. G. (2008). Kimia Pangan Dan Gizi: Edisi Terbaru. Jakarta. Gramedia Pustaka Utama, 31. 